\title{
Kant sobre a vontade: a influência luterana
}

\author{
Kant on the Will: The Lutheran Influence
}

\begin{abstract}
Resumo: A vontade racional (e a sua atividade como vontade pura) é a faculdade investigada por Kant na sua Metafísica dos costumes. Neste artigo, procuro esclarecer a concepção que Kant tem dessa faculdade, isto é, como um poder causal constituído por uma norma. Para tanto, são analisados três textos-chave de Kant. A comparação com a posição luterana sobre a concupiscência sugere uma forte influência dessa posição sobre a concepção kantiana da vontade.

Palavras-chave: Kant, vontade, poder constituído por norma, concupiscência, luteranismo.
\end{abstract}

*André Nilo Klaudat

Abstract: The rational will (and its activity as a pure will) is the faculty examined by Kant in his Metaphysis of Morals. In this paper I aim to clarify Kant's conception of this faculty, i.e. as a causal power constituted by a norm. To this end, I analyze three central texts by Kant. The comparison with the Lutheran view on concupiscence suggests a strong influence of it on Kant's conception of the will.

Keywords: Kant, Will, Power Constituted by a Norm, Concupiscence, Lutheranism.

\footnotetext{
* Doutor em Filosofia pelo University College London. Endereço postal: Departamento de Filosofia - IFCH, Rua Bento Gonçalves 9500, CEP: 91509-900, Porto Alegre, RS, Brasil. <klaudat@ufrgs.br>.
} 
Von dem Willen gehen die Gesetze aus; von der Willkür die Maximen. Die letztere ist im Menschen eine freie Willkür; der Wille, der auf nichts anderes, als bloss auf Gesetz geht, kann weder frei noch unfrei genannt werden, weil er nicht auf Handlungen, sondern unmittelbar auf die Gesetzgebung für die Maxime der Handlungen (also die Praktische Vernunft selbst) geht, daher auch schlechterdings notwendig und selbst keiner Nötigung fähig ist. Nur die W I l l - k ü $\mathrm{r}$ also kann $\mathrm{f} r$ e i gennant werden.

Die Freheit der Willkür aber kann nicht durch das Vermögen de Wahl, für oder wider das Gesetz zu handeln (libertas indifferentiae), definiert werden - wie es wohl einige versucht haben -, obzwar die Willkür als Phänomen davon in der Erfahrung häufige Beispiele gibt. [...] - Die Freiheit, in Beziehung auf die innere Gesetzgebung der Vernunft, ist eigentlich allein ein Vermögen, von dieser abzuweichen, ein Unvermögen. Wie kann nun jenes aus diesem erklärt werden?

Immanuel Kant, Die Metaphysik der Sitten (6:226-227)

\section{Introdução: o problema}

A ética é, segundo o Prefácio à Fundamentação da metafísica dos formal, que não tem nenhum) e que se ocupa com as leis da liberdade ${ }^{1}$. Ainda segundo o Prefácio, essa filosofia - a filosofia moral - tem a tarefa de definir as leis "da vontade do homem, na medida em que ela é afetada pela natureza"2. Mas, o que é a vontade da qual a filosofia moral define as leis? Qual é a concepção que Kant tem dela quando ela é claramente central para a sua articulação da ética? É a de uma faculdade? De que natureza? Essas perguntas ganham em importância quando consideramos uma filosofia moral que rivaliza com a de Kant e para a qual a vontade está seguramente em segundo plano.

1 Cf. KANT, Immanuel, Grundlegung der Metaphysik der Sitten, in: IDEM, Gesammelte Schriften, Berlin: Akademie der Wissenschaften, Band IV, 1911, 4:387. A Fundamentação da metafísica dos costumes será citada com o número do seu volume na Akademie-Ausgabe ("4"), seguido da página. O mesmo se dará para a Crítica da razão prática [Kritik der praktischen Vernunft] ("5") e para a Metafísica dos costumes [Die Metaphysik der Sitten] ("6"). Para a constituição do texto, utilizo as edições inglesas da Cambridge University Press (com tradução de Mary Gregor), de 1999 (cf. as "Referências", adiante), com exceção da Fundamentação da metafísica dos costumes, da qual utilizo a tradução para o português feita por Guido de Almeida, com algumas poucas alterações que aparecem entre chaves. As traduções do inglês são minhas, com cotejamento do texto alemão e das traduções de Valério Rodhen e de Edson Bini (cf. as "Referências", adiante).

2 Cf. KANT, Immanuel, 4:387-388; minha ênfase. 
David Hume trata da vontade no livro das paixões (o Livro II do Treatise ${ }^{3}$ ), e o faz somente na terceira parte ("Of the Will and Direct Passions"), quando o assunto são as paixões diretas, que são propriamente ativas, pois as indiretas (orgulho, humildade, amor e ódio) não costumam nos levar à ação. A vontade é, então, "definida" como um efeito imediato da dor e do prazer que não é propriamente uma paixão, mas antes o aspecto ativo ou de efetividade das paixões, duas características que distanciam essa concepção daquela da vontade como faculdade. A vontade é vista como certa atitude em relação às paixões: que é perceptível na consciência de estarmos sendo ativos quando intencionalmente fazemos algo movidos pelas paixões.

Eu gostaria que fosse observado que por vontade eu não quero significar nada senão a impressão interna que sentimos e da qual somos cientes quando intencionalmente $\left[{ }^{4}\right]$ damos lugar a qualquer novo movimento do nosso corpo ou nova impressão da nossa mente ${ }^{5}$.

O propósito de Hume ao introduzir o tema da vontade é, oficialmente, entender a sua natureza e as suas propriedades, das quais a mais importante é essa de operar com necessidade humeana. E isso permitirá a execução do projeto de explicação dos motivos que influenciam a vontade em geral (Seção 3) e em particular (restante da Parte III). A defesa de Hume da "necessidade" nas "ações da vontade" está a serviço do projeto da "ciência da natureza humana": "[...] tendo provado que todas as ações da vontade têm causas particulares, eu passo a explicar quais são essas causas e como elas operam" ${ }^{6}$. Trata-se da naturalização, aos olhos de Hume, das paixões e da vontade com vistas a uma correspondente naturalização da moral $^{7}$.

3 Cf. HUME, David, A Treatise of Human Nature, Oxford: Oxford University Press, 1978. As traduções feitas de passagens deste texto são minhas, sob consulta à tradução brasileira de Deborah Danowski.

4 O termo é "knowingly"; ele foi traduzido por Deborah Danowsky como "deliberadamente". Cf. HUME, David, Tratado da natureza humana, tradução de Deborah Danowski, São Paulo: Unesp, 2000, p. 435.

5 Cf. HUME, David, A Treatise of Human Nature, p. 399.

6 Id. ibid., p. 412.

7 O quadro humeano é mais complexo do que esses pontos indicam, bastando, para tanto, mencionar a teoria das paixões calmas. Mas, para quem vê Hume (e Hobbes) como um redutivista sobre a vontade, o costume é apontar para a semelhança entre Hume e, por exemplo, Harry Frankfurt, que sustenta (cf. FRANKFURT, Harry, Freedom of the Will and the Concept of a Person, in: IDEM, The Importance of What We Care About, Cambridge: Cambridge University Press, 1998, p. 14: "Identificar a vontade de um agente é ou identificar o desejo (ou desejos) pelo(s) qual(is) ele é motivado em alguma ação que ele realiza ou identificar o desejo (ou desejos) pelo(s) qual(is) ele irá ou iria estar motivado quando ou se ele age. A vontade de um agente, então, é idêntica a um ou mais dos seus desejos de primeira ordem. Mas, a noção de vontade, como eu a estou empregando, não é coextensiva à noção 
Quanto a Kant, ele insiste no mencionado Prefácio que o objeto da investigação fundacional da metafísica dos costumes é, em especial, a vontade pura, e não a vontade geral ${ }^{8}$. Segundo Kant, Wollf não considera esse tipo de vontade: "[uma vontade] que, sem quaisquer motivos empíricos, fosse plenamente determinada por princípios a priori e à qual se pudesse dar o nome de uma vontade pura" ${ }^{\text {. Não obstante as }}$ aparências, é realmente claro que se trate para Kant de uma espécie de vontade, identificada por gênero e diferença? Ou trata-se, antes, ao se falar de "vontade pura", de um tipo de motivação da vontade?

Kant concebe a tarefa de uma metafísica dos costumes como a de examinar a ideia e os princípios de uma possível vontade pura. E, para registrar o que há de especial nessa tarefa, Kant afirma que a psicologia geral não distingue motivos que "são [apresentados] pela mera razão de maneira plenamente a priori e que são propriamente morais dos [motivos] empíricos que o entendimento eleva a conceitos universais pela mera comparação de experiências"10. Daí o problema fundacional ser identificado em parte com o de esclarecer a fonte dos motivos da vontade, ou seja, dos tipos de motivação.

[...]. Sem atentar para a diversidade de suas fontes, [os autores da psicologia consideram-nos] tão-somente segundo a maior ou menor soma dos mesmos (na medida em que são considerados como sendo todos eles da mesma espécie), e desse modo formam seu conceito de obrigação, [conceito este] que é, na verdade, tudo menos moral, mas que é, no entanto, tal qual se pode de todo exigir em uma filosofia que não [julga] sobre a origem de todos os possíveis conceitos práticos, se têm lugar a priori ou apenas a posteriori ${ }^{11}$.

Mas, o que essa preocupação com a fonte dos motivos requer quanto à concepção da vontade, se ela não é propriamente compreendida como um gênero do qual a vontade pura seria uma espécie da qual Kant então teria, como tarefa exclusiva, provar a realidade?

A perspectiva teórica que essa questão exige é explicitamente discutida por Kant no Prefácio à segunda Crítica, em que a "faculdade de desejar" é apresentada de um modo filosoficamente neutro, de modo a não ser prejulgada a possibilidade de uma posição moral que envolva a

de desejos de primeira ordem. Não é a noção de algo que meramente inclina o agente em alguma medida a agir de certa maneira. Ao contrário, é a noção de um desejo efetivo - um que move (ou irá ou iria mover) uma pessoa por todo o caminho até a ação".

8 Cf. KANT, Immanuel, 4:390ss.

9 Id. ibid., 4:390.

10 Ibid., 4:391.

11 Ibid. 
atividade de uma razão prática pura, de uma vontade pura ${ }^{12}$. Na psicologia, precisamos admitir, em geral, que a determinação da faculdade de desejar não se dá exclusivamente pelo "sentimento" de prazer, sob pena de o "princípio supremo da filosofia prática" acabar, "necessariamente", por se revelar "empírico". Porém, qual é a concepção, pertencente à psicologia, que não prejulga essa questão e que, portanto, articula adequadamente - como é preciso - a relação da faculdade de desejar com o "sentimento" de prazer? É importante notar que o propósito de Kant, aqui, é oferecer essa articulação com vistas à correta acomodação do prazer nas operações de uma faculdade de desejar como a nossa, a saber, de fato afetada pela nossa sensibilidade. Esse ponto será chave para a sua defesa de que a razão prática pura pode ser um incentivo ${ }^{13}$, sem o que não haveria obrigação em relação a seres como nós (objeto do Capítulo 3 da segunda Crítica). Três são os conceitos fundamentais para isso. Às definições adicionarei alguns comentários iniciais:

(1) Vida: "é a faculdade de um ser de agir de acordo com leis da faculdade de desejar". Comentário: a referência a "leis" até mesmo na definição de "vida" com relação à faculdade de desejar (e não simpliciter, presumivelmente) é indicativa daquilo que, como veremos adiante, é fundamental na concepção de Kant da vontade.

(2) Faculdade de desejar: "é a faculdade de um ser de ser por meio de suas representações a causa da realidade dos objetos dessas representações". Comentário: quanto a essa definição, veremos também na sequência que as noções centrais exigem interpretação, a saber, (a) uma faculdade que é ativa "por meio de suas representações", (b) que é uma faculdade que "causa a realidade" dos objetos de suas representações e (c) que tal faculdade tem esses "objetos".

(3) Prazer: "é a representação da concordância de um objeto ou de uma ação com as condições subjetivas da vida, i.e., com a faculdade da causalidade de uma representação com respeito à realidade do seu objeto (ou com respeito à determinação dos poderes do sujeito para a ação a fim de produzir o objeto)". Comentário: digno de nota são, em primeiro lugar, as alternativas quanto à representação da concordância que é o prazer (portanto, ele mesmo uma relação: do sujeito com uma representação); pode-se tratar da concordância com um "objeto" da faculdade de desejar ou com uma "ação" da mesma. Em segundo lugar, algo surpreendentemente, a referência final à produção do objeto através de uma ação do sujeito, por oposição à "causalidade de uma representação com

12 Cf. KANT, Immanuel, 5:9n, de onde são tiradas as citações a seguir.

13 A saber, "Triebfeder". 
respeito à realidade do seu objeto", parece indicar que nessas ocorrências as alternativas "objeto" e "ação" estão a serviço dos casos, respectivamente, moral e não-moral (neste último, é por meio das nossas ações que tornamos existentes ou acessíveis "objetos" que satisfazem a vontade por corresponderem às nossas representações do que queremos).

O que é importante é que, a partir dessas definições, deveríamos poder ver que não se está prejulgando a questão sobre se na faculdade de desejar, em todas as suas operações, precisamos encontrar prazeres que as antecedem (que ela os envolva necessariamente parece estar sendo pressuposto): "se prazer precisa ser sempre posto à base da faculdade de desejar ou se sob certas condições o prazer somente se segue às suas determinações". O propósito teórico-filosófico é claramente o de não "antecipar nossos julgamentos através de definições", ou seja, resolver problemas filosóficos por meio de estipulações.

Não se trata, aqui, de examinar o que será a defesa completa da efetividade da "vontade pura", ou da razão prática pura, em relação ao seu "objeto", e nem de como Kant pode de modo a priori indicar qual é o efeito (portanto, necessário) dessa efetividade sobre a nossa humana sensibilidade, a saber, o sentimento de respeito. O meu propósito é somente o de examinar em três ocorrências-chave a concepção de vontade que parece ir adiante, em relação ao que a psicologia deveria nos oferecer em geral neutramente, o que por certo, ao menos, prepara o terreno para aquela defesa.

\section{Três textos sobre a vontade}

Nesta seção, eu gostaria de discutir três passagens seminais para a compreensão da concepção de Kant acerca da vontade. Elas parecem sustentar posições distintas, e é possível que, ao se dar ênfase aos aspectos nelas ressaltados, chegue-se a versões alternativas da concepção de Kant. A primeira passagem é, em geral, tomada como representativa do que seria fundamental nessa concepção. Na FMC, Kant famosamente afirma (Texto (A)):

Toda coisa na natureza [opera] segundo leis. Só um ser racional tem a [capacidade] de agir segundo a representação das leis, isto é, segundo princípios, ou uma vontade. Visto que se exige a razão para derivar de leis as ações, a vontade nada mais é do que razão prática ${ }^{14}$.

A orientação de interpretação de Kant, que faz dessa noção de capacidade ou poder de agir segundo a representação das leis - tomada

14 Cf. KANT, Immanuel, 4:412. 
em um sentido a ser explicado -, a noção central da concepção da vontade será aqui chamada de representacionalista.

O que é da definição de vontade, segundo essa orientação, é ela ser a capacidade de - ao agir "segundo a representação das leis" - agir por razões. A importância desse último conceito, por sua vez, é bem explicada por Anthony Kenny ${ }^{15}$. A vontade é uma capacidade comportamental que se expressa, primariamente, na agência voluntária ${ }^{16}$, por oposição à agência natural ${ }^{17}$. Além disso, seres humanos têm uma agência voluntária que se caracteriza pela volição, que é expressa na ação intencional ${ }^{18}$. Isso significa que seres humanos têm intenções, ao contrário dos animais, e aqueles as têm porque podem dar razões para as suas ações" 19 : "A capacidade de ações intencionais é a mesma coisa que a capacidade de agir por razões" ${ }^{20}$. A diferença a esse respeito entre animais e seres humanos é, primeiramente, que os últimos têm a habilidade de realizar ações que "respondem a certas descrições lingüísticas" 21 . O ponto fundamental, no entanto, é esse que vem a seguir, que concerne à ligação entre a racionalidade e a capacidade de dar razões, que então depende de algo mais do que da mera capacidade de agir segundo uma descrição linguística.

Seres humanos, dissemos, são diferentes de animais em função de poderem realizar ações como respondendo a uma descrição linguística particular. O mesmo é dito quando dizemos, em uma terminologia artificial [...], que seres humanos, diferentemente de animais, agem de acordo com volições. Mas, é claro que a diferença entre seres humanos e animais não é exaurida por isso. Mesmo a ação humana espontânea e impensada pode estar de acordo com uma volição. Se seres humanos são animais racionais, eles precisam ter um outra capacidade também: a habilidade de agir por razões.

Para se ter razões para agir é necessário, embora não suficiente, que se tenha a habilidade de reconhecer ações como caindo sob descrições linguísticas. Se alguém grita "sai do caminho" eu posso fazer isso espontaneamente, embora após refletir reconheça (diferentemente de um caixa de banco em um assalto) que eu não tinha nenhuma razão para fazê-lo. Para se ter razões para agir, nós precisamos ser capazes de dar razões para agir. Dar razões para agir pode tomar a forma de mostrar o bem (ou bem presumido) do ato ele próprio, ou de mostrar que ele era o meio para algum fim bom (ou presumido fim bom)"22.

15 Cf. KENNY, Anthony, The Metaphysiscs of Mind, Oxford: Oxford University Press, 1992, p. 32-49, de onde são tiradas as passagens no texto.

16 Id. ibid., p. 32-33.

17 Ibid., p. 34.

18 Ibid., p. 37.

19 Ibid., p. 39.

20 Ibid.

${ }^{21}$ Ibid., p. 40.

22 Ibid., p. 42. 
O motivo da orientação de interpretação de Kant ser representacionalista não é, então, que a referência à "representação das leis" exige a habilidade de agir em resposta a "descrições linguísticas"; antes, tratase dessa "representação" no texto de Kant ser compreendida como o oferecer, o dar razões para agir. Essas, por sua vez, no caso de Kant, procuram ser representações de leis vistas como a fonte do bem. Essa orientação é bem difundida.

Uma intérprete de Kant que segue essa orientação é Beátrice Longuenesse. A sua visão do texto de Kant citado é que a "representação das leis" em questão é essa "de leis que não são descritivas (tais como as leis naturais, que são descrições de correlações objetivas), mas prescritivas ou normativas. Quando Kant fala de imperativos, ele está obviamente falando [desse tipo] de leis"23. Mas, note-se bem: leis em geral. O quadro se completa com a visão do imperativo categórico como um "princípio de segunda ordem: a sua função é avaliar as regras que já temos resultantes de premissas hipotéticas que expressam relações prudenciais e instrumentais de fins e meios" ${ }^{4}$. Portanto, trata-se da sujeição de "regras que já temos" a uma lei em especial, o que implica que a vontade é compreendida como a capacidade de agir por regras, regras representadas como normativas pelo ser racional: "Um ser dotado de uma vontade é um ser dotado de uma faculdade de desejar que age não somente de acordo com leis, mas de acordo com a representação de leis" 25 .

Henry Allison também adota a orientação representacionalista sobre a vontade. Segundo ele, trata-se da capacidade de agir com base em princípios práticos. E, na medida em que esses devem ser distinguidos em objetivos e subjetivos, sendo que os últimos são aqueles segundo os quais os agentes agem efetivamente, alcançamos a visão de que "agir de acordo com a concepção de leis deve ser entendido como equivalente a agir com base em máximas" ${ }^{26}$. Allison ${ }^{27}$ esclarece que a sua visão é que agentes racionais agem em vista $d e^{28}$ princípios objetivos, e não de acordo com eles, sendo as máximas, então, os princípios de acordo com os quais os agentes efetivamente agem. Isso faz com que as máximas se reportem aos (e assim até mesmo, em algum sentido,

${ }^{23}$ Cf. LONGUENESSE, Beátrice, Kant on the Human Standpoint, Cambridge: Cambridge University Press, 2005, p. 250.

24 Id. ibid., p. 251.

25 Ibid., p. 251; ênfase minha. Note-se o sentido de "de acordo com leis", aqui, ou seja, ser conforme o que, por exemplo, uma lei natural prevê que sejam correlações objetivas entre objetos ou eventos. A insistência na "representação de leis" permite, então, a introdução dos imperativos, com as suas funções de controle de segunda ordem.

26 Cf. ALLISON, Henry, Kant's Theory of Freedom, Cambridge: Cambridge University Press, 1990, p. 85.

27 Id. ibid., nota 3.

${ }^{28}$ No original, "in light of". 
"representem" os) "princípios práticos objetivos"29. Ou seja, "agentes racionais adotam as suas máximas em vista de princípios práticos objetivos ou imperativos" ${ }^{30}$. É nesses termos que devemos compreender a famosa "tese da incorporação", de Allison. "Incentivos"31 determinam a vontade somente enquanto são "incorporados em uma máxima", e isso para ele quer dizer: "ao serem tomadas por um agente (ao menos implicitamente) como razões suficientes para a ação" ${ }^{22}$. Como isso exige somente que o agente adote a máxima segundo a presunção implícita de que ela está "em algum sentido justificado racionalmente" ${ }^{33}$, Allison abre espaço para a sua interpretação de que a "implícita suficiência" de razões garante a espontaneidade e a racionalidade até mesmo de ações baseadas em incentivos, ou seja, ações heterônomas ${ }^{34}$.

Allen Wood segue na mesma senda. Contudo, quanto à vinculação, por parte de Kant, da vontade com a escolha do que é praticamente necessário, ou seja, bom ${ }^{35}$, ele compreende o bom nesse contexto em termos das razões para nos constranger a perseguir o que eventualmente desejamo ${ }^{36}$. E, por esse motivo, esse "bom" não tem nada de especialmente moral: "Ver uma ação como boa é vê-la como aquela que deve ser feita em consequência de um princípio racional de alguma espécie, não importando nossos impulsos ou inclinações momentâneas (mesmo se a adoção do princípio racional seja ela própria baseada na inclinação)" 37 . FMC:

A segunda passagem - Texto (B) - é a que abre a terceira seção da

A vontade é uma espécie de causalidade de seres vivos na medida em que são racionais, e a liberdade seria aquela propriedade dessa causalidade na medida em que esta pode ser eficiente independentemente da determinação por causa alheias ${ }^{38}$.

${ }^{29}$ Ibid., p. 261, nota 3.

30 Ibid., p. 86.

31 Novamente, "Triebfedern".

32 Ibid., p. 126.

${ }^{33}$ Ibid., p. 268, nota 52; ênfase minha.

34 Ibid., p. 126. Sobre a interpretação de Henry Allison acerca desses pontos, e em especial sobre o caráter moderno da posição de Kant, cf. FLIKSCHUH, Katrin, Kantian Desires: Freedom of Choice and Action in the Rechtslehre, in: TIMMONS, Mark, Kant's Metaphysics of Morals. Intepretative Essays, Oxford: Oxford University Press, 2002, p. 185-207.

35 Cf. KANT, Immanuel, 4:412.

36 Cf. WOOD, Allen W., Kant's Ethical Thought, Cambridge: Cambridge University Press, 1999, p. 55.

37 Id. ibid., p. 55; ênfase minha. Note-se a interpretação com a qual Wood precisa se comprometer do seguinte texto da Fundamentação (cf. KANT, Immanuel, 4:413): "Bom em sentido prático, porém, é o que determina a vontade mediante as representações da razão, por conseguinte, não em virtude de causas subjetivas, senão objetivamente, isto é, em virtude de razões que são válidas para todo ser racional enquanto tal". Ou seja: há razões válidas para todo ser racional que não tem "nada de especialmente moral".

38 Cf. KANT, Immanuel, 4:446. 
Nessa passagem, o que é digno de nota, inicialmente, é a apresentação da vontade como uma causalidade. A referência à liberdade como uma "propriedade dessa causalidade" de ser eficiente independentemente de sua determinação por "causas alheias" sugere uma distinção quanto à operação dessa causalidade, entre ela ser eficiente ativamente e ser eficiente via "causas alheias", isto é, passivamente. A natureza dessa possibilidade será discutida abaixo. Mas, é claro que uma interpretação representacionalista procurará ressaltar nessa passagem a seguinte qualificação da referência à causalidade: "na medida em que são racionais". Ou seja, tratar-se-ia de uma causalidade que é eficiente em geral, por ser, como vimos, o comportamento por razões (no sentido apresentado).

A orientação que dá ênfase à causalidade na concepção da vontade em Kant será chamada de causalista. Deve-se notar, em primeiro lugar, que nem uma interpretação representacionalista, nem uma causalista, se atêm unicamente, respectivamente, à primeira e à segunda passagens aqui apresentadas. Trata-se do que se toma como fundamental para dar conta do que pode parecer recalcitrante em outras passagens. Daí ser perfeitamente aceitável para uma interpretação representacionalista notar a respeito da primeira passagem que o verbo "operar" remete a "produzir efeitos" ou "ser uma causa eficiente" 39 , fazendo com que a faculdade de agir dos seres racionais deva também ser vista como tal causalidade - de todo modo, como vimos, por razões, no sentido explicado.

Quanto a uma interpretação causalista, a defesa da centralidade da causalidade na concepção de Kant da vontade ganha apoio ao se constatar que, por exemplo, Christian A. Crusius oferece uma definição de vontade em termos muito próximos de Kant, mas que cuida de explicitar o papel da causalidade:

Por "vontade" eu entendo um poder da mente de agir de acordo com suas ideias. Eu quero dizer que a vontade é a causa eficiente, enquanto as ideias são o modelo ou a causa exemplar. Nós agimos de acordo com elas quando nós tornamos as coisas representadas reais ou tentamos fazê-lo ${ }^{40}$.

É possível compreendermos a especificidade de uma interpretação causalista considerando brevemente a sua interpretação associada de

39 Cf. a nota 70 de ALMEIDA, Guido de, in: KANT, Immanuel, Fundamentação da metafísica dos costumes, São Paulo: Barcarolla - Discurso, 2009, p. 312, que oferece esse comentário sobre "atuar".

40 Cf. CRUSIUS, Christian, A Guide to Rational Living (Psychology: Chapter 1: Of Goals and of the Human Will), in: SCHNEEWIND, J. (ed.), Moral Philosophy from Montaigne to Kant, Cambridge: Cambridge University Press, 2003, p. 569; ênfase minha. 
"máximas". Barbara Herman é uma importante representante desse tipo de interpretação. Para ela, máximas são vistas como representações de ações como essas são quistas (ou desejadas), e não como princípios sobre meios e fins aos quais ações são subsumidas. Ou seja, máximas não são meros princípios que especificam que certa ação, digamos, nessas circunstâncias, deve ser realizada para um determinado fim concebido como bom. Ao contrário, máximas são vistas por essa interpretação causalista como o modo de querer uma ação que é adequada para um fim na medida em que o agente julga que agir assim para esse fim é $b_{o m}{ }^{41}$. O que é próprio dessa interpretação é, em primeiro lugar, ver esse modo de querer como a concepção de se estar agindo "de acordo com um princípio ou padrão de valor"42; e, em segundo lugar, sustentar que "o padrão de valor ou a concepção do bem em termos do qual nós concebemos as nossas ações não podem ser alheios à vontade"43. Porém, em um sentido muito preciso, deve-se ver a vontade como constituída por uma lei do seu próprio poder causal ${ }^{44}$. Essa lei, é claro, é a lei moral. A interpretação, então, é a seguinte:

Um ser com uma vontade é certo tipo de causa: um [ser] capaz de iniciar uma ação ao derivá-la da sua representação do próprio princípio da vontade. Uma ação, assim derivada, é o que a máxima representa ${ }^{45}$.

[...]. Se a vontade racional é um poder causal, se ela é uma maneira distintiva de produzir coisas (ações), então o seu princípio ativo não será o princípio mecânico de causa e efeito (que, é claro, não produz coisas, mas explica as suas ocorrências), mas um princípio do tipo de causa que ela é - um princípio racional de causalidade. A fim de se falar da vontade de um agente racional, então, nós precisamos introduzir elementos conceituais que não seriam exigidos senão pela existência da vontade racional. Isso é metafísica $[\ldots]^{46}$.

${ }_{41}$ Cf. HERMAN, B., Bootstrapping, in: EADEM, Moral Literacy, Cambridge, Mass.: Harvard University Press, 2007, p. 169-170, sobre esses pontos. A conhecida concepção de Lewis W. Beck, que prevê que leis possam também ser máximas, parece próxima à posição de Herman. Quando uma lei é também uma máxima, temos de acordo com BECK, Lewis W., A Commentary on Kant's Critique of Practical Reason, Chicago: The University of Chicago Press, 1960, p. 82, a situação em que "um homem racional reconhece uma condição como presente e efetiva em todos os seres racionais como tais e, portanto, como válida e aplicável a ele próprio".

42 Cf. HERMAN, B., Bootstrapping, in: EADEM, op. cit., p. 170. Note-se que "de acordo com um princípio ou padrão" quer dizer, aqui, "por representação dele", em função dele por via de sua representação.

${ }^{43}$ Id. ibid.

44 Cf. sobre esse ponto o importante estudo de ENGSTROM, Stephen, The Form of Practical Knowledge. A Study of the Categorical Imperative, Cambridge, Mass.: Harvard University Press, 2009, passim.

45 Cf. HERMAN, B., Bootstrapping, in: EADEM, op. cit., p. 171.

46 Id. ibid., p. 173. 
Note-se, portanto, que essa interpretação causalista, aparências do contrário à parte, é admitidamente metafísica. Trata-se de conceber a vontade como um poder causal constituído por um "princípio racional de causalidade". Agentes racionais agem porque as suas ações são presumivelmente o resultado de um poder causal racionalmente constituído. Nesse sentido, podemos dar conta da "eficiência passiva" no exercício da vontade. Influências não-racionais (as "causas alheias") podem afetar a representação que fazemos da lei da própria vontade ${ }^{47}$. Desse modo, podemos agir em função do que nos representamos talvez erroneamente como a lei da própria vontade, mas só agimos porque essa lei é constitutiva desse poder.

Essa interpretação causalista se distingue, então, de uma representacionalista por sustentar que para a concepção de vontade racional em Kant é central a vinculação entre a capacidade de agir de acordo com princípios com o conteúdo de um princípio em particular.

Poderíamos ter pensado que ter uma vontade racional é ter uma vontade capaz de chegar à ação por razões, não causas, isto é, capaz de agir de acordo com princípios: toda espécie de princípios. Isso é verdadeiro, mas é também enganador. Há, de fato, duas opções: ou a capacidade de agir de acordo com princípios é completamente independente do conteúdo dos princípios, ou é uma capacidade cujo exercício depende de algum princípio que nos torna capazes de agir com base em outros princípios, mesmo os deficientes. Kant afirma a segunda opção ${ }^{48}$.

Até esse ponto, temos, então, duas orientações de interpretação sobre o modo como Kant concebe a vontade racional. Vejamos o terceiro texto Texto (C) -, e o que é saliente nele, para ver para onde pende a balança:

A faculdade de desejar é a faculdade de ser por meio de nossas representações a causa dos objetos dessas representações ${ }^{49}$.

A faculdade de desejar de acordo com conceitos, na medida em que o fundamento que a determina à ação reside nela mesma e não no seu objeto, é chamada de faculdade de fazer ou deixar de fazer como nos aprouver. [...]. A faculdade de desejar cujo fundamento determinante interno, portanto até mesmo o que a agrada, reside na razão do sujeito é chamada de vontade. A vontade, portanto, é a faculdade de desejar não tanto em relação à ação (como é a escolha), mas ao invés disso em relação ao fundamento que determina a escolha para a ação. A vontade ela mesma, falando estritamente, não tem fundamento determinante; na medida em que ela pode determinar a escolha, ela é ao invés a própria razão prática ${ }^{50}$.

\footnotetext{
47 Ibid., p. 171.

48 Cf. HERMAN, B., Obligatory Ends, in: EADEM, Moral Literacy, Cambridge, Mass.: Harvard University Press, 2007, p. 257.

${ }^{49}$ Cf. KANT, Immanuel, 6:211.

50 Id. ibid., 6:213.
} 
Essas são passagens da Seção II da Introdução geral à Metafísica dos costumes, que se pronuncia sobre a relação das faculdades da mente humana com as leis morais. Conforme esses textos, a vontade é (1) uma "faculdade de desejar" (Begehrungsvermögen); (2) como tal, é uma faculdade causal; (3) é uma faculdade de acordo com conceitos que tem o fundamento determinante para a ação nela mesma (e não no seu objeto), e só por isso pode fazer algo ou deixar de fazê-lo conforme isso lhe agradar; e (4) que, quanto ao que lhe agrada, tem um fundamento determinante interno na razão. A referência final ao (5) "fundamento que determina a escolha" pode sugerir um quadro, com relação à vontade, como aquele apresentado pela orientação representacionalista. No entanto, o que é central nessa passagem, de acordo com uma interpretação causalista, é a combinação, quanto à faculdade que é a vontade, entre tratar-se de uma faculdade causal e ter nessa medida um fundamento determinante à ação nela mesma (interno), sendo só por isso razão prática. A noçãochave, então, está em que a vontade ela própria não tem um fundamento determinante para ser posta em atividade, como ela faz com a escolha (que é antes um aspecto dela que uma função ou parte sua). Ela não é, por exemplo, uma faculdade de escolher princípios quanto à ação, o que exigiria que ela pudesse ou devesse de algum modo ser instruída nessa escolha. A vontade é, ao invés, uma forma de desejar constituída por um fundamento interno racional.

Essa idéia de que a vontade é, como faculdade, constituída por uma lei racional do seu poder causal pode ser o que Beck chama de a "nova definição" da vontade ela própria em Kant,

"com todas as consequências morais a serem extraídas dessa concepção. A vontade é a faculdade de agir de acordo com a concepção de lei, que não é o produto ou a descoberta do entendimento, mas da razão. Em contraste, os seus predecessores tinham pensado na vontade somente como desejo racional, isto é, a faculdade de agir de acordo com uma clara (racional) representação do objeto do desejo" 51 .

51 Cf. BECK, Lewis W., A Commentary on Kant's Critique of Practical Reason, p. 38. É difícil decidir se Beck é um seguidor da orientação causalista. Afinal, o autor, cf. id. ibid., p. 178, afirma por um lado que "a faculdade que torna uma regra da razão a causa eficiente de uma ação através da qual o objeto será tornado real é a vontade", e por outro ele parece restringir essa visão da vontade à Willkür como uma faculdade distinta da Wille, dizendo que "essa concepção da vontade, como uma faculdade de desejar guiada por uma regra da razão tomada como máxima, se torna posteriormente mais especificamente a Willkür". 


\section{Vontade e concupiscência em Kant}

O meu propósito, agora, é analisar esse elemento central da posição - a constituição por um fundamento interno racional - via uma tese de Kant que, à primeira vista, é extemporânea à discussão da Seção II da Introdução à Metafísica dos costumes. Trata-se da tese sobre a natureza da concupiscência, apresentada justamente no contexto da conceitualização da vontade.

A concupiscência (desejar algo intensamente) ainda [noch] precisa ser distinguida do desejo ele próprio, como um estímulo à determinação do desejo. Concupiscência é sempre uma modificação sensível da mente, mas uma que ainda não se tornou um ato da faculdade de desejar ${ }^{52}$.

O ponto central dessa tese é que a concupiscência não é um desejo formado, um ato da faculdade de desejar, mas uma orientação (um estímulo) quanto à formação de desejos propriamente ditos. É uma orientação ligada à "modificação sensível da mente". Quanto à concupiscência ainda (no sentido de também) precisar ser distinguida de desejos formados, a implicação é que algo outro já é assim distinguido, presumivelmente algo que seja outra orientação (outro estímulo) à formação de desejos. O texto anterior à passagem em tela distingue uma determinação da faculdade de desejar por "princípios racionais puros". Se a lei moral for um desses, então a implicação é que ela, e assim a moralidade, não está - como fonte de desejos - necessariamente em conflito com desejos formados. Kant explicita esse ponto quando trata do dever de beneficiência, bem mais adiante na Metafísica dos costumes. O tópico é a felicidade dos outros como um fim que é também um dever (o segundo subtítulo da Seção VIII, que é sobre deveres de virtude como deveres amplos), e essa felicidade é primeiramente vista como envolvendo o seu bem-estar natural. Diz Kant, surpreendentemente ${ }^{53}$ :

Bem-estar natural. A benevolência pode ser ilimitada, pois nada precisa ser feito com ela. Mas é mais difícil fazer o bem, especialmente se ele é para ser feito não por afeição (amor) pelos outros, mas por dever, ao custo do sacrifício da satisfação da concupiscência e do prejuízo ativo dela em muitos casos ${ }^{54}$.

O que é surpreendente é que fazer o dever não se oponha à nossa busca pela felicidade através da satisfação dos nossos desejos, mas à concupiscência como orientação quanto à formação de desejos. Como diz

${ }^{52}$ Cf. KANT, Immanuel, 6:213; ênfase minha.

53 Cf. HERMAN, B., The Will and Its Objects, in: EADEM, Moral Literacy, Cambridge, Mass.: Harvard University Press, 2007, p. 230-253, em que a autora trata da importância dessa tese e do seu uso estratégico na discussão da natureza da vontade em Kant.

54 Cf. KANT, Immanuel, 6:393. 
Herman: "desse modo, o conflito por princípio não é entre a felicidade ou o desejo e a moralidade, mas entre a moralidade e uma fonte de desejo"55.

O Dicionário Houaiss, no verbete "concupiscência", registra duas acepções iniciais como ordinárias: "1. Cobiça de bens materiais 2 . Anelo de prazeres sensuais"; e duas acepções filosóficas: "3. FIL No agostinismo, luxúria carnal, desejo libidinoso 4. FIL No tomismo medieval, desejo de prazer gerado por realidade física, material". Esse dicionário registra ainda uma acepção teológica pejorativa: "6. TEOL pej. Cobiça natural do homem pelos bens terrenos, conseqüência do pecado original e que produz desordem dos sentidos e da razão"56. Não é claro que o ponto fundamental da tese de Kant sobre a natureza da concupiscência como algo que opera antes dos desejos seja capturada por alguma dessas acepções (a teológica pode ser a mais próxima). O meu propósito é averiguar se esse elemento teórico fundamental pertencente à concepção de Kant da vontade não pode ser mais bem compreendido à luz da posição luterana sobre a concupiscência. O objetivo é lançar luz sobre o referido elemento central da concepção de Kant.

\section{Pecado original e concupiscência no luteranismo}

\section{Lutero escreve o seguinte, no seu Comentário à Epístola aos Gálatas:}

Quando Paulo diz que a carne milita contra o espírito ${ }^{57}$, e o espírito contra a carne, ele nos admoestou que nós sentiremos a concupiscência da carne, isto quer dizer, não somente o desejo carnal, mas também orgulho, ódio, opressão [heaviness], impaciência, incredulidade, e similares. [...] É como se Paulo dissesse o seguinte: eu sei que a carne os provocará para o ódio, a inveja, a dúvida, a incredulidade, e similares: mas resistam a eles pelo espírito, que vós não pequeis. Mas se vós abandonardes a orientação do espírito, e seguirdes a carne, vós satisfareis o desejo da carne e vós morrereis [...]. Desse modo isso que diz o apóstolo deve ser entendido, não somente como desejos carnais, mas todo o reino do pecado ${ }^{58}$.

Note-se que a "concupiscência da carne" não é meramente um desejo formado de prazer carnal, é antes "todo o reino do pecado". Filipe Melanchthon, na sua Apologia da Confissão, esclarece qual é a posição luterana sobre a concupiscência. Logo no Artigo II, sobre o

55 Cf. HERMAN, B., The Will and Its Objects, in: EADEM, op. cit., p. 232.

56 Cf. HOUAISS, A., Dicionário Houaiss da Língua Portuguesa, Rio de Janeiro: Editora Objetiva, 2001, p. 789.

57 No alemão do próprio Lutero: "Denn das Fleisch begehrt auf gegen den Geist [...]" (cf. Gálatas 5.17).

58 Cf. LUTHER, Martin, A Commentary on St. Pauls Epistle to the Galatians, in: DILLENBERGER, John (ed.), Martin Luther - Selections from his Writings, New York: Anchor Books, 1962, p. 145. 
pecado original, temos a apresentação da compreensão desse pecado e da natureza da concupiscência a ele vinculada ${ }^{59}$.

A confutação papal da Confissão de Ausburgo (1530) insistia que os reformadores se equivocavam quanto ao pecado original ser nascer sem temor de Deus, sem confiança Nele, pois, segundo um sólido bom senso, "estar sem temor de Deus, sem confiança em Deus, antes é culpa atual de adulto que ofensa de infante recém-nascido, o qual ainda não possui ricamente o uso da razão"60. Consequentemente, a confutação só pode condenar os reformadores luteranos sobre o pecado original, quando "chamam de concupiscência a falta original, se querem dizer que a concupiscência é pecado assim, que continua pecado numa criança mesmo depois do batismo" 61 .

Segundo Melanchthon, o que sustentam os luteranos é que, para quem nasce "propagado segundo a natureza carnal", atribui-se a concupiscência que impede que ele possa temer e confiar verdadeiramente em Deus, mas isso não como ato, mas como potência contrária a essa relação com Deus: “[...] Ao fazermos menção da concupiscência entendemos não só os atos ou frutos, mas também a contínua inclinação da natureza"62.

Há quem sustente não ser o pecado original vício ou corrupção na natureza humana, mas apenas servidão ou condição da mortalidade que a descendência adâmica, sem qualquer vício próprio, suporta por culpa alheia. Acrescentam, além disso, que ninguém é condenado à morte eterna em razão do pecado original, assim como de escrava nascem escravos e suportam essa condição sem vícios de natureza, mas em virtude da desgraça materna. Para significar que essa opinião ímpia nos desagrada, fizemos menção da concupiscência, e, muito bem intencionados, a chamamos de enfermidade e expusemos que a natureza dos homens nasce corrupta e viciosa ${ }^{63}$.

Melanchthon insiste na inépcia dos "doutores escolásticos" que não compreendem bem a definição do pecado original recebida dos Pais da Igreja, assim diminuindo a importância desse pecado. Eles entendem esse pecado como "fomes", como qualidade do corpo ${ }^{64}$.

${ }^{59}$ Cf. MELANCHTHON, Felipe, Apologia da Confissão de Augsburgo, in: Livro de Concórdia - As Confissões da Igreja Evangélica Luterana, tradução de Arnaldo Schüler, São Leopoldo: Editora Sinodal e Editora Concórdia, 1997, p. 95-304.

60 Cf. a nota 8, do tradutor, in: id. ibid., p. 100.

${ }^{61}$ Cf. a nota 8, do tradutor, in: ibid.

62 Ibid., p. 100.

63 Ibid., p. 101.

64 "Fomes" é sinônimo de "concupiscência"; contudo, a acepção que importa aos reformadores é aquela de "fomes oder Böse Neigung" (inclinação má); cf. a nota 16, do tradutor, in: ibid., p. 101. 
Para os reformadores, o problema com o pecado original é que em função dele o ser humano carece de "justiça original". Esse pecado é essa carência. Essa justiça, ensinada na primeira tábua do Decálogo, que contém os mandamentos de amor a Deus, é a "semelhança divina" posta no homem por Deus que o criou, e ela se manifesta não na adequação de ações comuns, mas na "notícia mais certa de Deus, [no] temor de Deus, [na] confiança nele"65. Ou seja, "a definição antiga, quando diz que o pecado é carência de justiça, não só nega a virtude da obediência no que diz respeito às forças inferiores do homem, senão ainda nega notícia de Deus, confiança em Deus, temor e amor de Deus, ou, certamente, a força para efetuar estas coisas" ${ }^{66}$. Portanto, o problema não diz respeito "somente aos atos", mas ao se negar o temor de Deus e a confiança nele, o que se nega são os "dons e o poder para efetuá-los". Note-se bem: para Melanchthon, os atos não serão efetuados com a orientação certa sem o poder conferido pela "justiça original".

O rationale para a visão luterana do pecado original como concupiscência compreendida como carência de "justiça original" se encontra em Agostinho. Segundo Melanchthon, para Agostinho o fundamental é que, após a perda daquela justiça, vem a concupiscência: "Porque a natureza enferma, não podendo temer, amar e crer a Deus, busca e ama as coisas da carne" ${ }^{67}$. Isso significa que a concupiscência não é somente a privação de Deus, mas "o hábito vicioso que lhe sucedeu": ela "não é apenas corrupção das qualidades físicas, senão também depravada mudança paras as coisas carnais nas virtudes [ou forças] superiores"68. Desse modo, ter concupiscência é, em função da carência da justiça original, buscar "não só a volúpia física, senão também sabedoria e justiça carnais, e [confiar] nesses bens, desprezando a Deus"69. E, contra a posição da confutação, não se trata de "culpas atuais estar sem temor de Deus e sem fé. São imperfeições duradouras em natureza não renovada"70.

Essa referência a "imperfeições duradouras" é crucial para um ponto da dogmática luterana: o pecado original permanece após o batismo. A visão luterana desse pecado não é a de um mero "hábito corrupto", produzido pela carência de "justiça original", que representaria uma espécie de desordenamento das "partes da alma", algo corrigível, talvez permanentemente, com a ajuda de Deus e com o esforço humano.

\footnotetext{
65 Ibid., p. 103.

66 Ibid., p. 104.

67 Ibid.

68 Ibid.

69 Ibid.

70 Ibid., p. 105.
} 
A imperfeição é duradoura, segundo os reformadores. Esse ponto é importante para o meu propósito.

Segundo Melanchthon, quando Lutero ensina que o pecado original "sobre-resta ao batismo", ele só quer dizer que o batismo "destrói a culpa", mas que "permanece o materiale do pecado", ou seja, a concupiscência, e quanto a essa Lutero ensina que "o Espírito Santo, dado pelo batismo, começa a mortificar a concupiscência e cria novos motivos no homem"71. Esse é o ponto central: a criação de novos motivos no homem. Melanchthon cita Agostinho:

A concupiscência da carne é remitida no batismo, não de modo que deixe de existir, mas de maneira que não é imputada como pecado. Ainda que sua culpa já está absolvida, permanece, contudo, até que seja sarada toda fraqueza pela progressiva renovação do homem interior, de dia em dia, quando o homem exterior for revestido de incorruptibilidade ${ }^{72}$.

E Melanchthon frisa que nessa passagem se conhece que o pecado existe, portanto que permanece, embora não seja imputado. Essa é a concepção central: daquilo que existe como potência que ainda não gerou atos pelos quais possamos ser imputados. Melanchthon cita novamente Agostinho em um texto contra Juliano, onde essa concepção é articulada:

A lei que está nos meus membros fica remitida pela regeneração espiritual e remanesce na carne mortal. Fica perdoada porque a culpa fica remitida no sacramento, pelo qual os crentes renascem; permanece, contudo, porque gera desejos contra os quais batalham os crentes ${ }^{73}$.

No final do Artigo II, Melanchthon indica o que é exigido filosoficamente por uma teologia como a proposta pelos luteranos. Equivocadamente, as escolas trouxeram da filosofia para a teologia posições não aceitáveis pela teologia dos reformadores. Por exemplo, "que nada é pecado, a menos que seja voluntário"74. Ora, esse não é o caso justamente com o pecado original. Melanchthon esclarece que isso está bem quanto à "justiça civil", mas não quanto à "justiça divina". O que não se pode fazer é "diminuir o pecado original" procurando domesticá-lo para os trâmites da "doutrina filosófica ou secular sobre os costumes", desse modo "alimentando a confiança nas forças humanas e destruindo o conhecimento da graça de Cristo"75. Trata-se da teologia da "magnitude do pecado original" e da "fragilidade humana" que exigem a graça de Cristo para não ser

\footnotetext{
71 Ibid., p. 106.

72 Cf. a nota 45, do tradutor, in: ibid., p. 107 (passagem completa aditada).

${ }^{73}$ Ibid., p. 107; ênfase minha.

74 Ibid., p. 108.

75 Ibid.
} 
imputado e da presença do Espírito Santo para ser mortificado ${ }^{76}$. Segundo essa teologia, o homem não pode com as suas próprias forças cumprir os mandamentos de Deus e superar a servidão na natureza humana, que é "cativa do diabo". Segundo Melanchthon, o Gênesis ensina que a natureza humana não está sujeita somente "à morte e a outros males corporais, mas também ao reino do diabo"77.

Pois a natureza humana foi entregue à servidão, permanecendo cativa do diabo, que a enlouquece com opiniões ímpias e erros, e a impele a toda espécie de pecados. Mas assim como o diabo não pode ser vencido senão com o auxílio de Cristo, da mesma forma não podemos libertar-nos dessa servidão por nossas próprias forças ${ }^{78}$.

A indicação de Melanchthon é que é preciso filosoficamente conceber essa "falha" da potência para "toda espécie de pecado". Ou seja, conceber a natureza de um pecado involuntário. É claro que, para a teologia cristã, isso requer, para ser sanado enquanto culpa, a graça de Cristo, e enquanto inquebrantável tendência à mortificação da concupiscência pela fortaleza do Espírito Santo requer uma reorientação, gerando atos de uma natureza reformada ("renovada"), embora não alterada, isto é, permanentemente reequilibrada. Estamos, com isso, imersos na teologia da "justificação pela graça mediante a fé", o lema luterano, mas examinemos agora a importância filosófica do elemento central à elaboração apresentada: a possibilidade da criação de novos motivos no homem. Voltemos à concepção da vontade em Kant.

\section{A vontade como um poder constituído por normas em Kant}

$\mathrm{Na}$ posição luterana sobre a natureza do pecado original, não encontramos nada explícito sobre a faculdade da vontade. Mas, nela claramente se destaca a concepção da concupiscência, não como "ato", uma ação do sujeito, de sua "faculdade de desejar", um desejo formado, antes como "contínua inclinação da natureza" para uma espécie de desejos, ou seja, como uma fonte de desejos, ao invés de desejos particulares. Ora, esse ponto parece ser exatamente o fundamental para a concepção de Kant da vontade. Para ele, a ação por dever está em choque com a concupiscência assim entendida, e não necessariamente com os desejos já formados pertencentes ao nosso anseio pela felicidade.

\footnotetext{
76 Ibid.

77 Ibid., p. 109.

78 Ibid; ênfase minha.
} 
Como vimos no início, a filosofia moral de Kant é a filosofia que concebe a moralidade como fruto da vontade pura. Trata-se de uma filosofia para a qual a vontade como faculdade é crucial para que a moralidade tenha o conteúdo que tem. Não se poderia identificar a fonte da motivação da vontade pura se a vontade fosse concebida à maneira de Hume, como um conjunto estável de "desejos" (paixões) refletidamente endossados em uma dinâmica instituída pela nossa natureza e pelo mundo. Para Kant, trata-se de uma faculdade, com uma tarefa específica a desempenhar na constituição da agência racional. Como ela faz isso? Como ela é, afinal, quando ela precisa poder fazer isso?

O que chama a atenção na passagem de Kant sobre a concupiscência é que ela "ainda precisa ser distinguida do desejo ele próprio, como um estímulo à determinação do desejo"79. Ora, isso exige que o "estímulo à determinação do desejo", que é diferente da "modificação sensível da mente", também seja visto como anterior a um ato da faculdade de desejar ${ }^{80}$. Isso, por sua vez, torna a faculdade de desejar, que é a vontade, uma faculdade não definida pela presença de desejos formados. A vontade, então, como faculdade de desejar sujeita também àquele outro tipo de estímulo não é uma faculdade de desejos já formados. Nesse sentido, Kant dá ênfase à atividade de desejar, antes que aos efeitos da presença de desejos na vontade. Isso permite a ele, como vimos, não abandonar o elo entre desejar e ter prazer, mas conceber o prazer como anterior e como posterior ao desejo, isto é, como envolvido na determinação do ato de desejar um objeto como resultado da nossa ação e como o efeito do nosso interesse por um tipo de ação ${ }^{81}$.

Esse ponto sobre a centralidade da forma de desejar também foi encontrado na posição luterana sobre a concupiscência. Como vimos, para Melanchthon, o Espírito Santo através do batismo começa a "mortificar" a concupiscência e, assim, cria a possibilidade de "novos motivos no homem", algo pelo que precisamos zelar, na busca de uma - nas palavras de Agostinho - "progressiva renovação do homem interior".

Se estivermos certos, o que exatamente substitui a palavra de Cristo, a sua graça e a ação do Espírito Santo na atividade da vontade, que está à altura da "justiça original", na concepção de Kant dessa faculdade, quando sua atividade é essencial à moralidade?

${ }^{79}$ Cf. KANT, Immanuel, 6:213; ênfase minha.

80 Id. ibid.

${ }^{81}$ Cf. HERMAN, B., The Will and Its Objects, in: EADEM, op. cit., p. 235: "Note-se que, ao associar prazer com desejo, não há confusão entre o prazer que pode ser o fim da ação e o prazer que acompanha a atividade. O que Kant faz é mover o desejo para longe do sentimento, aproximando-o da atividade, oferecendo um estado separado, a relação em-direção-a [towardrelation], que ocorre ou antes ou depois do desejo, dependendo se ela ou algo outro determina a faculdade de desejar a desejar". 
Vimos que a orientação de interpretação chamada de causalista sustenta a centralidade de que a vontade em Kant seja uma forma de desejar que é constituída por um fundamento interno que reside na razão. Esse último aparece, então, como definidor de uma capacidade, de desejar de acordo com conceitos racionais, ou seja, o que importa para essa orientação é a existência de um "fundamento que determina [a faculdade de desejar] à ação [que] reside nela mesma" ${ }^{82}$. Como é possível tal capacidade? Que capacidade é essa?

A interpretação causalista de Herman apresenta, nesse ponto, a concepção de poderes constituídos por normas em geral, para dar conta dessa dificuldade ${ }^{83}$. Um dos casos usados para ilustração dessa concepção é o do professor. Como professor, alguém tem o poder de dar notas. Claro que se trata do poder de dar notas conforme avaliações de mérito. Trata-se de um poder conferido institucionalmente e definido em termos específicos. Uma pessoa, tendo esse poder, por ser professor(a), pode também, por certo, usá-lo mal. Mas, quanto à condição de um mau uso, é crucial notar algo. Dar notas seguindo um padrão estético para a atribuição de As, Bs e Cs, ou, em uma imagem cara a certos professores, dar notas de aprovação a provas ou trabalhos que caem sobre uma mesa quando todos são jogados para o alto ante a mesma, não é claramente um uso do poder de avaliar (pode-se pensar que sim, em função de se tratar nominalmente de "avaliar" devido ao fato de se estar na posição de fazê-lo). Porém, dar notas por favoritismo ou por se aceitar suborno é um uso do poder conferido de avaliar que é um mau uso. O poder em questão, note-se bem, é o poder de dar notas por mérito, e não o de dar notas por mérito ou por favoritismo, etc, o que, obviamente, não exclui a possibilidade do referido mau uso do poder. Para se notar a diferença: quando se usa mal o poder do modo referido, exercita-se o poder, enquanto no outro caso não se chega a ser um avaliador propriamente dito (não se está supondo que esse seja o modo de avaliação de mérito presumivelmente adotado por algum professor, não há por que imaginar que possa sê-lo, afora o gosto pelo insólito).

O que esse tipo de caso deveria permitir que víssemos é que há poderes constituídos por normas para o seu exercício perfeito, e, portanto, que o seu mau uso importa uma incapacidade quanto a esse seu uso. Em uma adaptação mais provável do caso do professor: dar notas por mérito em função de convicções ideológicas quanto ao mérito é uma incapacidade de dar notas por mérito, mas normalmente um exercício do poder ou da capacidade em questão.

82 Cf. KANT, Immanuel, 6:213.

${ }^{83}$ Cf. HERMAN, B., The Will and Its Objects, in: EADEM, op. cit., p. 249ss; e HERMAN, B., Obligatory Ends, in: EADEM, op. cit., p. 256ss. 
Quanto à vontade, existiria, então, uma lei que é constitutiva do próprio poder causal da vontade: a lei moral, como lei da liberdade. Não se trata tanto de um princípio normativo para as melhores (porque suficientes) razões para a ação; antes, trata-se do princípio normativo para se ter razões simpliciter ${ }^{84}$ :

"A afirmação mais difícil que Kant faz sobre o padrão geral para a correção da ação é que ele é suprido pela lei moral como o princípio constitutivo da vontade racional - da escolha livre. É difícil tanto porque é difícil compreender como esse princípio poderia ser uma parte necessária ou uma condição do querer em geral, como é difícil aceitar que o princípio da moralidade seja necessário para a liberdade de escolha - difícil se não por outra razão que a dificuldade de então ter de se explicar escolhas "ruins". O problema é que a posição de Kant não é somente a de que a lei moral é de algum modo a condição metafísica da liberdade da vontade, tornando a escolha livre tanto possível quanto não forçada. Ao invés disso, a total estranheza da posição está em que o exercício mesmo de escolhas ruins depende de algum modo da lei moral como o seu fundamento determinante" 85 .

O meu propósito, aqui, não é examinar o porquê de Kant sustentar que a lei moral seja efetivamente a lei constitutiva do poder causal que define a vontade. Trata-se somente de articular a concepção de que essa lei possa ser tal lei constitutiva, e que assim toda escolha livre de ações dependa desse princípio da própria razão. A orientação causalista, então, prevê que para um agente racional querer alguma coisa ele precisa conceber a si mesmo como sujeito de tal ato de volição, isto é, conceber a si mesmo como uma "causa" que age em função de seus fins. Mas, é quanto a esses fins que a orientação causalista é específica ${ }^{86}$.

$\mathrm{O}$ agente racional age em função de se representar querendo um fim, mas isso agora quer dizer: agir de acordo com a representação do princípio constitutivo da vontade, isto é, como um poder de produzir efeitos em função desse princípio. No caso desse princípio ser a lei moral, seria ela, então, que o agente racional representaria na sua escolha racional e como condição dessa. Se ele a representa corretamente, então

84 Cf. HERMAN, B., The Will and Its Objects, in: EADEM, op. cit., p. 251: "O poder da vontade, da nossa espécie de faculdade de desejar, nos habilita para ações por razões. Isso não é meramente a ação acompanhada pelo pensamento da justificação, mas a ação a partir de razões que estão submetidas a um padrão de correção para razões".

85 Cf. HERMAN, B., Obligatory Ends, in: EADEM, op. cit., p. 257.

${ }^{86}$ Cf. HERMAN, B., The Will and Its Objects, in: EADEM, op. cit., p. 246ss, para os pontos a seguir. 
ele de fato vê que a lei moral é o princípio de justificação último para a sua ação ou o princípio do bem presente na mesma. O ponto crucial é que, ao representá-la mal, o agente racional ainda age tendo como princípio de possibilidade da ação a lei moral:

[...] Quer a volição específica do agente esteja ou não em conformidade com a lei moral (quer ela a represente precisamente), a lei moral sempre é a condição de um querer possível, e assim é, nesse sentido, o seu princípio. Nós desse modo explicamos como pode ser tanto o caso que a vontade é a razão prática e que as nossas vontades [willings] não sejam necessariamente boas - elas não seguem necessariamente o princípio da razão ${ }^{87}$.

\section{Considerações finais}

Voltemos, então, ao que foi referido anteriormente como a noçãochave da concepção de vontade de Kant (a propósito do texto "C"): essa faculdade não tem ela própria um fundamento determinante para ser posta em atividade, como ela faz em relação à escolha. Diferentemente do caso do professor, quando alguém pode escolher ou não seguir a profissão, quando da escolha e da ação simpliciter não nos é facultado o uso da vontade racional. Há um padrão de correção para o querer racional. E como ele é um padrão, segundo a interpretação causalista, constitutivo do poder que é a vontade, ele não pode por isso ser escolhido, ou recusado, embora como padrão ele se pronuncie sobre todos os outros fins que possamos ter, como a sua condição de possibilidade. Nos termos de Barbara Herman: "A vontade como um poder de agir livremente dá aos seres racionais o fim de conformarem a sua atividade à norma do querer livre" 88 . Trata-se de um fim formal, não um fim no sentido de "fim a ser produzido ou alcançado", mas no sentido de ser um padrão para os possíveis fins que podemos eleger ${ }^{89}$.

Nesse sentido, a vontade em Kant tem uma norma que é constitutiva do seu poder como faculdade racional, uma norma anterior a desejos formados, orientando justamente a atividade de desejar racionalmente (não só de modo moral). O que parece fundamental a essa concepção é que não há de fato a liberdade - a suposta liberdade de indiferença

Id. ibid., p. 246.

88 Ibid., p. 251.

89 Cf. HERMAN, B., Rethinking Kant's Hedonism, in: EADEM, Moral Literacy, Cambridge, Mass.: Harvard University Press, 2007, p. 192, para evitar equívocos na caracterização desse modo de operação da lei moral. É de se esperar que, nessa orientação de interpretação, a lei moral apresente aos seres racionais "razões morais para viver uma vida de maior ao invés de menor complexidade", como maneira de fazer justiça à dignidade humana como fim em si mesmo. 
dos incompatibilistas - de escolha entre essa norma e, digamos, a concupiscência. Na eventualidade dessa segunda opção, há de fato um Unvermögen. Essa pode muito bem ser a versão filosófica da "vontade cativa" dos luteranos, que não tem ligação direta com os assuntos da justiça humana ${ }^{90}$.

\section{Referências}

ALLISON, Henry. Kant's Theory of Freedom. Cambridge: Cambridge University Press, 1990.

BECK, Lewis W. A Commentary on Kant's Critique of Practical Reason. Chicago: The University of Chicago Press, 1960.

CRUSIUS, Christian. A Guide to Rational Living (Psychology: Chapter 1: Of Goals and of the Human Will). In: SCHNEEWIND, J. (ed). Moral Philosophy from Montaigne to Kant. Cambridge: Cambridge University Press, 2003. p. 569-584.

ENGSTROM, Stephen. The Form of Practical Knowledge. A Study of the Categorical Imperative. Cambridge, Mass.: Harvard University Press, 2009.

FLIKSCHUH, Katrin. Kantian Desires: Freedom of Choice and Action in the Rechtslehre. In: TIMMONS, Mark. Kant's Metaphysics of Morals. Intepretative Essays. Oxford: Oxford University Press, 2002. p.185-207.

FRANKFURT, Harry. Freedom of the Will and the Concept of a Person. In: IDEM. The Importance of What We Care About. Cambridge: Cambridge University Press, 1998. p. 11-25.

HERMAN, B. Bootstrapping. In: EADEM. Moral Literacy. Cambridge, Mass.: Harvard University Press, 2007. p. 154-175.

Obligatory Ends. In: EADEM. Moral Literacy. Cambridge, Mass.: Harvard University Press, 2007. p. 254-275.

. Rethinking Kant's Hedonism. In: EADEM. Moral Literacy. Cambridge, Mass.: Harvard University Press, 2007. p. 176-202.

. The Will and Its Objects. In: EADEM. Moral Literacy. Cambridge, Mass.: Harvard University Press, 2007. p. 230-253.

HOUAISS, A. Dicionário Houaiss da Língua Portuguesa. Rio de Janeiro: Editora Objetiva, 2001.

90 A Seção IX de LUTHER, Martin, Bondage of the Will, in: DILLENBERGER, John (ed.). Martin Luther - Selections from his Writings, New York: Anchor Books, 1962, tem o título: "Que a vontade que não tem o poder sem a graça não é livre". Segundo Lutero, cf. id. ibid., p. 187, "o 'livre arbítrio' sem a graça de Deus não é de modo algum livre, mas é prisioneiro permanente e escravo do mal, pois ele não pode voltar a si mesmo para o bem". O livre arbítrio (cf. ibid., p. 188) concebido como "poder de livremente voltarmo-nos para qualquer direção, não cedendo a ninguém e sujeito a ninguém" é uma "ideia falsa, uma verdadeira ameaça à salvação" (cf. ibid., p. 189). Podemos, no entanto, segundo Lutero (cf. ibid., p. 189), "creditar ao homem 'livre arbítrio' com respeito não ao que está acima, mas ao que está abaixo dele", embora "com respeito a Deus, e a tudo o que toca à salvação e danação, ele não tem "livre arbítrio', mas é cativo, prisioneiro e escravo, ou à vontade de Deus, ou à vontade do diabo" (cf. ibid., p. 190). 
HUME, David. A Treatise of Human Nature. Oxford: Oxford University Press, 1978. Unesp, 2000.

Tratado da natureza humana. Tradução de Deborah Danowski. São Paulo:

KANT, Immanuel. Grundlegung der Metaphysik der Sitten. In: IDEM. Gesammelte Schriften, Berlin: Akademie der Wissenschaften, Band IV, 1911.

. Fundamentação da metafísica dos costumes. Tradução de Guido A. de Almeida. São Paulo: Barcarolla - Discurso, 2009.

Kritik der praktischen Vernunft. In: IDEM. Gesammelte Schriften. Berlin: Akademie der Wissenschaften, Band V, 1913.

$\overline{\text { Fontes, }} 2002$.

Crítica da razão prática. Tradução de Valério Rohden. São Paulo: Martins

Critique of Practical Reason. In: The Cambridge Edition of the Works of Immanuel Kant - Practical Philosophy. Transl. Mary Gregor. Cambridge: Cambridge University Press, 1996. p. 135-271.

. Die Metaphysik der Sitten. In: IDEM. Gesammelte Schriften. Berlin: Akademie der Wissenschaften, Band VI, 1914.

. A metafísica dos costumes. Tradução de Edson Bini. São Paulo: Edipro, 2008.

. The Metaphysics of Morals. In: The Cambridge Edition of the Works of Immanuel Kant - Practical Philosophy. Transl. Mary Gregor. Cambridge: Cambridge University Press, 1996. p. 365-603.

KENNY, Anthony. The Metaphysiscs of Mind. Oxford: Oxfrod University Press, 1992.

LONGUENESSE, Beátrice. Kant on the Human Standpoint. Cambridge: Cambridge University Press, 2005.

LUTHER, Martin. A Commentary on St. Pauls Epistle to the Galatians. In: DILLENBERGER, John (ed.). Martin Luther - Selections from his Writings. New York: Anchor Books, 1962. p. 96-165.

. Bondage of the Will. In: DILLENBERGER, John (ed.). Martin Luther - Selections from his Writings. New York: Anchor Books, 1962, p. 166-203.

MELANCHTHON, Felipe. Apologia da Confissão de Augsburgo. In: Livro de Concórdia - As Confissões da Igreja Evangélica Luterana. Tradução de Arnaldo Schüler. São Leopoldo: Editora Sinodal e Editora Concórdia, 1997. p. 95-304.

WOOD, Allen W. Kant's Ethical Thought. Cambridge: Cambridge University Press, 1999.

Recebido em: 26.03.2015

Aprovado em: 30.06.2015 